\title{
O PESADELO DE DARWIN: UM OLHAR REFLEXIVO SOBRE AS RELAÇÕES NORTE-SUL DESDE O LAGO VITÓRIA - TANZÂNIA. ${ }^{1}$
}

Juliane Bernardes da Silva ${ }^{2}$

Resumo: A questão econômica nos países do chamado Terceiro Mundo ou subdesenvolvidos se encontra num entrelaçamento entre pagar a dívida externa e prover o bem estar da sociedade local. Entretanto, diversos são os interesses que convergem para práticas de exploração econômica, e pouco interesse com a desigualdade social gerada. É a partir desse cenário de exploração de capital e contrabando de armas que o documentário Darwin's Nightmare é produzido; através da introdução e desenvolvimento de uma espécie de peixe chamada Perca do Nilo e sua exportação para Europa, toda uma população ao redor do Lago Vitória se vê subjugada e explorada, me utilizando dessa analogia do mais forte subjugar o mais fraco, me propus a discutir o documentário e as conjunturas sociais e econômicas vivenciadas na Tanzânia.

Palavras chave: Tanzânia, neoliberalismo, economia, exclusão social.

Resumen: La cuestión económica en los países del llamado Tercer Mundo o subdesarrollados se encuentra en un imbricamento entre pagar la deuda externa y proveer el bien estar de la sociedad local. Sin embargo, diversos son los intereses que convergen para prácticas de explotación económica, y poco interés con la desigualdad social generada. Es a partir de este escenario de explotación de capital y contrabando de armas que el documental Darwin's Nightmare es producido; mediante la introducción y desarrollo de una especie de pez llamada Pierda del Nilo y su exportación para Europa, toda una población alrededor del Lago Victoria se ve subjugada y explorada, utilizándome de esa analogía del más fuerte subjugar el más

\footnotetext{
${ }^{1}$ Este texto foi produzido como trabalho de fim de curso para matéria Tópicos Especiais em África, ministrada pelo Professor Hector Guerra Hernandez.

${ }^{2}$ Aluna da graduação em História na Universidade Federal do Paraná. É bolsista no projeto de extensão "Escravidão e formação do Estado brasileiro nas fontes judiciais do Paraná (1822-1888): descrição de documentos e ampliação de instrumentos de pesquisa".
} 
débil, me propuse a discutir el documental y las coyunturas sociales y económicas vivenciadas en Tanzania.

Palabras clave: Tanzania, neoliberalismo, economía, exclusión social.

\section{Breve história da formação da Tanzânia}

A Tanzânia é um dos maiores países do continente africano. Com $886.000 \mathrm{~km}^{2}$ aproximadamente, faz divisa com o Quênia, Uganda, Ruanda, Burundi, Zâmbia, Malawi, e Moçambique, seu litoral é banhado pelo Oceano Índico, onde possui três ilhas; além do Lago Vitória, Lago Niassa e Lago Tanganica banharem o território. Atualmente, a população da Tanzânia é de 47.879.000 habitantes, com uma variação de 157 grupos étnicos catalogados.

O território da Tanzânia como se configura hoje é resultado de um acordo depois de um conflito em que uniu Zanzibar, - uma das ilhas costeiras e importante entreposto comercial entre o continente africano, Ásia e Europa - e Tanganica, formando assim a Tanzânia. Antes da chegada e ocupação dos colonizadores europeus, os árabes detinham grande influência, entre os séculos IX e XII, realizando casamentos, controlando as rotas de caravanas para o interior do continente e as rotas comerciais marítimas ao longo da costa oriental ${ }^{3}$. Quando os

\footnotetext{
${ }^{3}$ Worldmark Enciclopedia of the Nations, Twelfth Edition, Africa Vol. 2. States of America, 2006, pp .683
} 
europeus se estabeleceram, em meados do século $\mathrm{XV}$, a prática comercial já estava estabelecida e a escravidão também fazia parte dessa sociedade.

A colonização da região ocorreu entre alemães e britânicos no final do século XVIII. Depois de acordos firmados, o sultão de Zanzibar perdeu o controle sobre a região e o território foi dividido em 1890. Tanganica, Ruanda e Burundi ficaram sob domínio alemão, Zanzibar e Pemba sob controle inglês, cada qual estabelecendo nas respectivas regiões companhias a fim de explorar o território ${ }^{4}$.

A ocupação efetiva do território se deu depois de conflitos entre os militares alemães e os líderes locais. Em 1907 ocorreu a revolta de Maji-Maji, uma das mais expressivas rebeliões, na qual um líder espiritual reuniu diversos clãs e fez frente às forças alemãs - que, como qualquer outro país imperialista em território africano, usava da força para explorar os recursos naturais e explorava também a mão de obra local. Entretanto, os colonizadores saíram vencedores ${ }^{5}$. Depois dessa revolta, que deixou 250.000 mortos devido à fome e ao próprio conflito, instaurou-se um governo civil, e como governador foi escolhido o

\footnotetext{
${ }^{4}$ Idem.

${ }^{5}$ Idem.
} 
Conde Albrecht von Rechenberg, que procurou estabilizar as relações entre os colonos africanos ${ }^{6}$.

Após a Primeira Guerra Mundial e a derrota alemã, os britânicos passaram a ocupar toda a Tanganica por meio de uma espécie de mandato, que foi expedido pela Liga das Nações a partir de 1920, e a política de administração indireta, já implementada em outras colônias, foi também empregada nessa região. Mas a condição de exploração não diminuiu e a situação continuava insatisfatória para a população africana. Depois da participação de contingentes africanos, tanto na Primeira quanto na Segunda Guerra Mundial, as elites e a população local passaram a cobrar das autoridades sua independência ${ }^{7}$.

Assim como em outras colônias, Tanganica tinha certa representatividade política, mesmo que com expressão menor do que a dos colonizadores. Entretanto, o movimento pan-africanista ${ }^{8}$ e o fim da Segunda Guerra fortaleceram os líderes políticos locais. De acordo com

\footnotetext{
${ }^{6}$ Encyclopedia of Twentieth-Century African History. New York, London: Routledge, 2002 , pp. 542.

7 Op. cit., loc. Cit.

${ }^{8} \mathrm{O}$ movimento pan-africanista surgiu entre os séculos XVIII e XIX entre os representantes negros dos países americanos. O objetivo destes era lutar contra o racismo, dominação e exploração branca sobre os negros. A participação de expressão africana no pan-africanismo se deu a partir de 1945 no Congresso Pan-africano que ocorreu em Manchester, sendo a principal reivindicação a descolonização de todo o território africano. (De acordo com o discutido em aula durante o curso de História da África HH117, $1^{\circ}$ semestre de 2013).
} 
Michael Twaddle, o principal motivo de descontentamento "foi a ingerência maciça dos britânicos na política agrícola africana que desencadeou a primeira grande onda de protestos locais contra a potência colonial" 9 . Sendo assim, esse descontentamento fortaleceu as relações entre as populações locais que procuraram formar associações a fim de lutar por melhores condições sociais e econômicas, já que as políticas coloniais, principalmente a agrícola, estavam provocando diferenciações muito amplas.

A organização entre as reivindicações urbanas e camponesas ocorreu através da TAA (Tanganika African Association), que buscou unificar as reivindicações e consequentemente se fortaleceu politicamente. Em 7 de julho de 1954, o que era a TAA se transformou no partido União Nacional Africana do Tanganica - TANU, fundado por Julius Nyerere ${ }^{10}$. Este usou a diplomacia e, por meio da ONU, procurou estabelecer a independência de Tanganica, que desde 1946 passou a ser um protetorado inglês "sob tutela da ONU", condição que desagradou os ingleses. A força partidária do TANU ficou evidente em 1960, quando conquistou 70 das 71 cadeiras do Conselho Legislativo, e

\footnotetext{
9 TWADDLE, Michael. A África Oriental. In. MAZRUI, A.A. História Geral da África vol. VIII - África desde 1935. São Paulo: Ática/UNESCO, 1991, pp. 274 ${ }^{10}$ Ibidem, pp. 275.
} 
em dezembro de 1961 conquistou sua independência e Nyerere, com claras tendências socialistas, foi escolhido como presidente ${ }^{11}$.

Zanzibar depois de diversos conflitos internos que visavam o estabelecimento de um governo, em 26 de abril de 1964 foi unificado com a Tanganica, e, em outubro do mesmo ano, de República Unida de Tanganica e Zanzibar, passou a se chamar Tanzânia, mas não sem conflitos internos. Entretanto, mesmo depois da unificação, Zanzibar continuou a ter um governo independente do continente ${ }^{12}$.

\section{Tanzânia pós-colonial}

Depois de conquistada a independência, os problemas de política interna e externa se mostraram notáveis. Para além do apoio aos países vizinhos, como Moçambique, Rodésia do Sul e África do Sul, que buscavam também libertar-se do julgo colonial, as relações entre a Comunidade do Leste Africano - Quênia, Uganda e Tanzânia - foram abaladas devido diferenças políticas. As fronteiras entre Tanzânia e Uganda foram fechadas e houve conflito militar direto entre 30 de

\footnotetext{
${ }^{11}$ Ibidem, pp. 277.

${ }^{12}$ Worldmark Enciclopedia of the Nations, Twelfth Edition, Africa Vol. 2. 2006, pp. 683.
} 
outubro de 1978 até $1982^{13}$, quando o governo ugandense de Idi Amin foi derrubado. Este conflito ocorreu após a tentativa de anexação do território de Kagera, pertencente à Tanzânia, pelo governo de Uganda. Idi Amin após ser derrotado foi exilado na Líbia, depois Arábia Saudita, aonde veio a falecer ${ }^{14}$.

A política interna também sofreu alguns reveses. Depois de reeleito em 1980, Nyerere enfrentou desgastes. Primeiramente com a tentativa frustrada de um golpe militar em 1983, além dos conflitos políticos entre Zanzibar e o continente que eram corriqueiros. Após forte pressão, o presidente Aboud Jumbe, que reivindicava mais autonomia para a ilha, renunciou ao cargo de presidente de Zanzibar e de vice-presidente da Tanzânia, e em seu lugar foi eleito Ali Hassan Mwinyi em 1984. E em novembro de 1985 Mwinyi foi eleito presidente, e em 1990 foi reeleito ${ }^{15}$.

A organização partidária da Tanzânia, assim como em qualquer país, não poderia deixar de ser conflituosa. Primeiramente a consolidação de um sistema multipartidário foi lenta; e, mesmo depois de estabelecida nova organização, as divergências entre os partidos são defrontados de forma violenta.

${ }^{13}$ Idem.

${ }^{14}$ New Encyclopedia of Africa. Vol. I. States of America, 2008, pp. 262.

${ }^{15}$ Op. cit. p.684. et. seq. 
Antes da independência havia mais de um partido, tanto em Tanganica como em Zanzibar. Em 1977 os partidos ASP (Afro-Shirazi Party) de Zanzibar e o TANU foram unificados, criando o CCM (Chama Cha Mapinduzi) e tornando-se os partidos mais influentes da ilha e do continente. As eleições para a Assembleia Nacional eram internas, mas não sem competitividade. Como apresentado anteriormente, Nyerere foi o primeiro presidente eleito e depois Mwinyi ocupou a presidência, ambos eleitos para presidência do Partido e presidente do país ${ }^{16}$.

Num primeiro momento o CCM, sob a liderança de Nyerere (1994-1995), buscava igualdade social, autoconfiança, cooperação econômica com outros países africanos e desenvolvimento da economia, em especial a economia rural a fim de fortalecer os camponeses ${ }^{17}$. Porém, a partir de 1980 o partido começa a se tornar a favor de uma economia liberal, e práticas pró-mercado começam a ser adotadas e, concomitantemente, o CCM, mesmo que ainda muito forte e influente, começa a se desgastar e se divide regionalmente. Em 1992 a Tanzânia volta a ser multipartidária, mas o CCM ainda é maioria e sua influencia nas eleições é contundente ${ }^{18}$.

\footnotetext{
${ }^{16}$ Ibidem, pp. 686.

${ }^{17}$ Op. cit., loc. Cit.

${ }^{18}$ Op. cit. p.684. et. seq.
} 
A primeira tensão entre os partidos se deu nas eleições de 1995, quando o CCM ganhou as eleições do CUF (Frente Cívica Unida) em Zanzibar. O CCM foi acusado de fraude nas eleições, alguns integrantes do CUF foram presos e, apesar de tentar boicotar o reconhecimento do candidato eleito, Salmir Amour e os demais eleitos para deputados foram reconhecidos. Os conflitos eleitorais são constantes e mesmo com cerca de doze partidos, o CCM permanece com maioria na Assembleia, sempre elegendo seu candidato a presidência ${ }^{19}$.

\section{O Lago Vitória}

Um dos Grandes Lagos, o Vitória, está localizado na África Oriental é partilhado por Uganda, Quênia e Tanzânia, e possui 68.870 km², sendo o maior lago africano. Em 1858 o britânico John Henning Speke, em expedição na região, em busca da origem do rio Nilo, encontrou o lago e o batizou de Vitória em homenagem à rainha Vitória, acreditando ser este a nascente do Nilo.

Por abranger uma vasta região, a pesca no Lago Vitória historicamente foi importante para a subsistência da população local. Entretanto, a pesca comercial provocou diversas transformações. A

\footnotetext{
${ }^{19}$ Idem.
} 
implementação de novos utensílios, como a rede, ocupou o lugar de técnicas utilizadas pela população local, o que, além de diminuir o espaço dos pescadores locais, a quantidade de peixes decaiu e consequentemente um meio importante de subsistência foi de alguma forma afetado. Outro problema foi à introdução da espécie de peixe Perca do Nilo, que transformou a economia e toda a sociedade local.

A Perca do Nilo foi introduzida no Lago Vitória em 1950, com objetivo único de aumentar a produção e exportação de peixe, essa a espécie foi escolhida por poder pesar até $200 \mathrm{~kg}$. Esse peixe fomentou o comércio pesqueiro na região; entretanto, por ser uma espécie predadora, os demais peixes do Lago foram dizimados pela perca, ou seja, a população local foi obrigada a se alimentar dessa espécie de peixe, e o ecossistema foi alterado, afinal a perca dizimou as espécies nativas. Foi também inserida no lago uma espécie de vegetal aquático para tornar o ambiente mais belo, devido ao turismo e à pesca esportiva desenvolvida na região. Por fim, a construção de barragens para hidroelétricas também está alterando o nível da água em alguns pontos do $\operatorname{lago}{ }^{20}$.

20 ALVES, Breno Souza. Lago Vitória: exemplo da falta de conhecimento científico. Disponível em <http://scienceblogs.com.br/discutindoecologia/2008/12/ lago-vitoria-exemplo-da-falta-de-conhecimento-cientifico/> acesso em: 24/07/2013. 


\section{O Pesadelo de Darwin}

A partir desse contexto conturbado - liberalismo econômico, divergências partidárias, problemas sociais - que o documentário Darwin's Nightmare - O Pesadelo de Darwin - aborda a pesca no Lago Vitória e suas consequências.

O documentário foi produzido em 2004 pelo austríaco Hubert Sauper. O filme tem duração de 107 min. e a narração é realizada por Sauper. Recebeu prêmios entre 2004 e 2006, entre os quais se destacam o de melhor documentário no European Film Academy em 2004, no Festival Internacional de Viena também em 2004, no Festival de Cinema de Sydney no ano de 2005, além da indicação ao Oscar de melhor documentário em 2006.

Logo na primeira cena do filme um avião sobrevoa o Lago Vitória, sendo essa cena repetida várias vezes, se tornando muito significativa durante todo documentário, isto porque no decorrer das entrevistas. Além das questões relacionadas à pesca indiscriminada e exclusão social, foram abordadas questões referentes ao envio de armas aos países vizinhos à Tanzânia através do aeroporto de Muansa. O contrabando de armas se esconde atrás da exportação de peixes, isso porque os aviões, supostamente, chegam carregados com armas e 
voltam para Europa com a Perca do Nilo. Essa informação é tratada a todo o momento no documentário. Enquanto a grande maioria dos entrevistados afirma, com certa hesitação, que os aviões chegam vazios, outros afirmam chegar com ajuda humanitária e talvez com armamentos, e há um que afirma enfaticamente o envio de armas para a África pela Tanzânia.

Como citado anteriormente, no decorrer do documentário são abordadas diversas questões sociais que envolvem a economia pesqueira. Optamos por abordar algumas delas, sendo essas a prostituição, o HIV, as crianças de rua e o destino dos peixes.

A prostituição fica evidente já nas primeiras cenas, e alguns fatores favorecem essa prática: um deles é a presença dos pilotos, mas a pobreza é apontada como a causa principal que levaria diversas mulheres a se prostituir. $\mathrm{O}$ documentarista questiona esta prática, ao que os entrevistados respondem que são as contingencias que levam diversas mulheres a se prostituir, isso porque muitas não têm família, trabalho ou outro meio de sustento.

Eliza é uma das prostitutas entrevistadas, conta que seus pais estão mortos e que não há outra forma de sobreviver, mas que mesmo diante dessas circunstâncias tem o sonho de estudar e melhorar de vida - outros entrevistados também apontam a necessidade de estudar para 
tentar sair da pobreza. Ela e outras moças se relacionam com os pilotos, e algumas afirmam que existe o risco de maus tratos por parte desses homens, entretanto, são eles que oferecem bebida e alimento, além do dinheiro. Numa das últimas cenas, Sauper em conversa com algumas dessas moças, informa ao espectador que Eliza foi morta por um cliente australiano.

Outro exemplo apresentado pelo diretor são as mulheres que vivem nas aldeias de pescadores, cujos esposos em algum momento saíram do interior onde eram agricultores, e se dirigiram ao Lago para trabalhar na pesca, e, devido ao HIV ou acidentes de trabalho, acabaram morrendo. Devido à falta de recursos, essas mulheres também se deslocam até o Lago, e por falta de opção acabam se tornando prostitutas, ficando tão expostas aos perigos da AIDS ou da violência física quanto às prostitutas que se relacionam com os pilotos.

A prostituição geralmente leva a contrair o vírus HIV, sendo os mais afetados pela doença os pescadores e as prostitutas. Sauper ao retratar uma comunidade de pescadores destaca a constante presença de prostitutas, bem como a prevenção quase nula contra o vírus. O padre da ilha de Quilimilile diz que uma média de 45 a 50 pescadores morrem a cada seis meses, devido à AIDS ou à pobreza, embora a pesca seja 
abundante, ela é destinada a exportação, e o trabalho do pescador é visivelmente desvalorizado e mal pago.

O filme retrata constantemente uma reação em cadeia de acontecimentos. Uma das cenas mais impactantes do documentário é quando diversas crianças de rua brigam entre si por uma porção mínima de alimento. Tais crianças são órfãs ou foram abandonadas pelos pais. A orfandade e o abandono seriam motivados pela pobreza e incapacidade econômica dos pais em criar seus filhos. Além disto, terse-iam os casos em que enquanto os pais estão trabalhando, as crianças ficam na rua e expostas aos mais diversos perigos. Sauper entrevistou várias dessas crianças, a maioria meninos, que dizem não ter pra onde ir: aqueles cujos pais são pescadores e passam a maior parte do tempo trabalhando ficam na rua - aparentemente por não existir um programa de educação eficiente -, e aqueles que são órfãos permanecem nas ruas devido à falta de assistência social. Um menino mais velho afirma que as que mais sofrem por viver nas ruas são as meninas, pois além de toda privação por estar na rua, ainda corre o risco de serem abusada sexualmente. Outro assunto abordado é a drogadição entre essas crianças e adolescentes, o que os torna ainda mais vulneráveis.

Por fim a destinação dos peixes: a produção de Perca do Nilo é enorme e extremamente rentável. Entretanto, como apontado acima, a 
produção é para exportação e a renda gerada é distribuída entre a população de forma desigual, vide as condições precárias em que vivem os pescadores. Em um dado momento um empresário indiano, proprietário de uma das empresas exportadoras da Perca, diz que a comunidade ao redor do Lago depende da pesca para sua sobrevivência. As empresas geram inúmeros empregos, e o fluxo da exportação é grande: segundo esse mesmo empresário, uma média de 500 toneladas de peixe são exportadas por dia. Apesar de ele estar certo ao dizer que as empresas são importantes, as imagens demonstram a pobreza que circunda a região, a falta de infraestrutura urbana e a fragilidade social existente além da oferta de empregos. As partes do peixe que não são exportadas, ou seja, os restos são defumados e vendidos para a população. A imagem do local onde ocorre esse processo é angustiante, além da falta de higiene e as condições de trabalho são desumanas. O contraste entre riqueza e pobreza é notório.

Outra questão importante relacionada à exportação do peixe é referente aos aviões e seu carregamento, como já mencionado. Nas filmagens, a maioria dos entrevistados é unânime em dizer que os aviões chegam vazios e partem com o carregamento de peixe, porém há evidencias de que existe o transporte de armas para o continente africano, e estas são usadas pelas guerrilhas ou pelo exército de países 
vizinhos a Tanzânia. Ao perguntar às prostitutas se sabem se algum tipo de armamento é transportado por seus clientes elas riem. Um adolescente ex-morador de rua, que atualmente é pintor, relata que já ocorreram apreensões de cargas com armamentos, e que a imprensa relatou o ocorrido, mas o presidente do país não deu muitos esclarecimentos. No fim do documentário um repórter é enfático ao dizer que existe um contrabando de armas, e que entram no continente pela Tanzânia, e afirma que são os países europeus que as enviam, e que a mortandade de africanos gera riqueza para europeus. Usando suas próprias palavras: "é tudo negócio".

A pesca no Lago Vitória é sim de extrema importância para a economia, mas é também uma cortina para esconder negócios escusos cujos responsáveis não querem ser relacionados, pois o envio de alimentos e medicamento a quem necessita é mais prodigioso que o envio de armas e financiamentos para as guerras.

\section{O desenvolvimento e o seu custo}

O liberalismo econômico nos países da África, assim como em todos do dito Terceiro Mundo, acarretou um processo de privatizações constantes e endividamentos impagáveis. Inicialmente, os empréstimos 
concedidos a esses países foram feitos a juros baixos, e devido ao desgaste da moeda norte americana somado com uma taxa de crescimento anual favorável, as dívidas poderiam ser pagas concomitantemente ao desenvolvimento do terceiro mundo. Porém o crescimento desses países não era visto com bons olhos pelas potências e uma nova política de juros bem mais altos foi introduzida, criando a necessidade da realização de novos empréstimos a fim de saldarem os antigos.

Essa temática é abordada por Patrick Bond, no livro A pilhagem na África, no qual o autor argumenta que as variações do PIB, os empréstimos internacionais e a as falsas doações para ajuda humanitária afligem e tornam os países do Terceiro Mundo mais dependentes e endividados $^{21}$. Diversos são os interesses em volta dos empréstimos e ajudas - envio de alimento ou investimentos - e, segundo Bond, cada liberação de empréstimos ou amortização da dívida externa vem carregada de contrapartidas que o país beneficiário deve arcar entre as quais está a liberação de mercado e possibilidades de privatização de serviços essenciais, como água, luz e educação ${ }^{22}$.

21 BOND, Patrick. A pilhagem da África, A economia da exploração. Trad. BLAJBERG, Salomon; BLAJBERG, Jennifer Dunjwa; LARA, Flavio Wanderlei. Rio de Janeiro, 2007, p.15-17.

${ }^{22}$ Ibidem, pp. 31-86. 
Com a taxa de juros em alta, a economia se estrutura a fim de pagar seus dividendos devido a grande pressão exercida e porque, caso os países emergentes ou subdesenvolvidos não consigam pagar anualmente o que foi previsto da dívida, diversos bancos mundiais poderiam quebrar e uma possível crise financeira se instauraria. Sendo assim, medidas de contenção de gastos públicos são adotadas: a abertura da economia para estabelecimento de empresas privadas e internacionais, a ausência de subsídios para agricultores é imposta, a monocultura é adotada e a necessidade de importar o que não se produz é inevitável. O controle do país passa para empresas privadas e às grandes instituições financeiras mundiais, pois ao reservar dinheiro público a fim de pagar a dívida, o orçamento para investir em questões públicas básicas é desnivelado, o que acarreta em privatizações do serviço público e, consequente, a exclusão social. Ao transferir obrigações do governo para empresas privadas, o maior prejudicado é a população, que em sua maioria é pobre e não consegue acesso a serviços básicos, apesar de existir políticas para educação, saúde e seguro social. Diante da desigualdade social se instaura a violência, promovida pelo Estado ou pela população.

Jean e John Comaroff no livro Violencia y ley en La poscolonia: uma reflexión sobre las complicidades Norte-Sur, abordam como a lei 
está inserida no imaginário social e como ela passou a influenciar as relações entre a sociedade e os governos, e como a violência entre estes é entendida e praticada ${ }^{23}$. Primeiramente, a desigualdade gera violência a partir do momento em que não se consegue obter os produtos que são comercializados ou não se tem acesso a direitos básicos, apresentandose então questionamentos e atos violentos. As oportunidades de se corromper num estado liberalista e obter ganhos maiores são constantes e amplamente difundidos. Isso se reflete no fato de que a grande maioria das empresas privadas só conseguiu se estabelecer em território africano mediante pagamento de propina: o próprio Sauper relata que teve que pagar propina a diversos policiais para conseguir passar por determinados locais.

Dentro de um quadro de desigualdade se cria meios de sobrevivência, que infelizmente perpassam o campo da violência, sendo essa mesma motivada por grandes investidores estrangeiros, e também utilizada para exemplificar a ingerência africana sobre seus territórios. Jean e John Camaroff afirmam que esse quadro de corrupção e violência é importante para desviar a atenção de problemas sociais causados pelo neoliberalismo e que, embora o continente africano seja tido como incapaz ou frágil para tratar de seus problemas, estes são os

\footnotetext{
${ }^{23}$ COMAROFF, Jean; COMAROFF, John L. Violencia y ley em La poscolonia: uma reflexión sobre las complicidades Norte-Sur. Madrid: Katz, 2009, pp. 63.
} 
mesmos enfrentados em todo o mundo, mas é na África que se encontram os produtos, meios e condições para a exploração de mercado $^{24}$.

\section{Considerações finais}

O nome do documentário é bem sugestivo: ao relacionar Darwin, a primeira coisa que vem a cabeça é a seleção natural e adaptação ao meio. Partindo desse pressuposto, podemos formular a pergunta: quem se adapta e quem é o mais forte no contexto do Lago Vitória? A população miserável se adapta ao meio, sobrevive como consegue, enquanto a perca do Nilo - que é tida como uma espécie predadora, inserida em um ambiente que a forçou a se adaptar -, os empresários, o governo e contrabandistas de armamentos são os selecionados pelo meio e aqueles que subjugam os demais em beneficio próprio. Essa é a lei do mercado, fatura mais quem se adapta melhor as contingências do momento.

Ao adotar uma política neoliberal, a partir dos anos 80 a Tanzânia possibilitou a entrada de diversas empresas para explorar seu território, e como diz um entrevistado do documentário:

\footnotetext{
${ }^{24}$ Idem.
} 
"Deus criou o mundo mas deu uma quantidade limitada de matéria prima. A humanidade luta por esta matéria prima. Antigamente brigavam por causa do território na África. Agora é por causa da matéria prima na Terra. Quem pode receber e quem não? Isto é a lei da selva"

Sendo assim, as possibilidades de se avançar no campo social em um país onde interesses de grandes potências estão em jogo são difíceis, mas não impossíveis, desde que se deseje a mudança. Os interesses do homem não são distintos de país para país, todos querem o poder, e quando o tem, querem mais, para acumular bens materiais e financeiros, nem que para isso outros sejam massacrados.

Assim como o desenvolvimento da Perca é predatório, as políticas econômicas também o são. Além de criar uma polarização mundial em torno de distribuição de renda, programas de auxilio humanitário vêm carregados de consequências deficitárias; os governos de países desenvolvidos se desvinculam da responsabilidade de acabar com a pobreza com uma ajuda ínfima e carregada de condições; os governos locais, por falta de opção, por ingerência ou ainda, por ganhos diretos com as políticas neoliberais, transformam a população pobre refém de um sistema que a exclui e marginaliza cada vez mais. Tudo isso porque a lei do mais forte prevalece. 
Aquela imagem de pobreza e savana deu lugar a uma reflexão de como os discursos do homem se repetem com o tempo. A África sempre foi considerada incapaz de se autogerir, e, apesar das independências, o discurso se repete: se antes a escravidão era o problema, agora a corrupção e a falta de tecnologia são prerrogativas para a ocupação de território e exploração de mão de obra.

Ao fazer uma busca rápida na internet com as palavras chave Tanzânia e pesca -, é possível encontrar os mais diversos sites de jornais internacionais reportando a ajuda de países europeus para economia tanzaniana ou ugandense, seja por meio financeiro ou de envio de alimentos para assistência humanitária. Mas aí cabem questionamentos que o documentário e a bibliografia utilizada proporcionaram: mais dinheiro para um maior endividamento e maior dependência, ou simples assistencialismo? Envio de alimentos para os que passam fome e vivem na miséria ou envio de armas escondidas no avião para continuar alimentando a predação que a perca simboliza? Evidente que os dois lados - potências econômicas e governantes africanos - ganham com essa política, mas a que custo? Políticas econômicas que realmente visem à redução da pobreza e da desigualdade social são necessárias, mas sem o que Bond chama de ajuda fictícia - aquelas que são mascaradas com interesses 
econômicos ${ }^{25}$. A procura por soluções para que essas questões sejam resolvidas necessita de um questionamento profundo do paradigma desenvolvimentista dominante, do contrário, muitas populações continuarão condenadas a reproduzir o mesmo processo predatório que tornou a perca do Nilo no triste símbolo do capitalismo contemporâneo nas margens do Lago Vitoria.

\section{Referências Bibliográficas}

ALVES, Breno Souza. Lago Vitória: exemplo da falta de conhecimento científico. Disponível em <http://scienceblogs.com.br/discutindoecologia/2008/12/lago-vitoriaexemplo-da-falta-de-conhecimento-cientifico/> acesso em: 24/07/2013.

África Num Mundo Globalizado. Caderno de Textos de Apoio. Ciclos Intergrados de Cinema, Debates e Colóquios na FEUC. Coimbra, 20052006.

BOND, Patrick. A Pilhagem da África, A Economia da Exploração. Trad. BLAJBERG, Salomon; BLAJBERG, Jennifer Dunjwa; LARA, Flavio Wanderlei. Rio de Janeiro, 2007.

${ }^{25}$ BOND, Patrick. op. cit., loc. cit. 
Revista Vernáculo, $n^{o} 30,2^{\circ}$ sem/2012

COMAROFF, Jean; COMAROFF, John L. Violencia y ley em La poscolonia: uma reflexión sobre las complicidades Norte-Sur. Madrid: Katz, 2009.

LAKE VICTORIA. In. Encyclopedia of African History and Culture. Vol. I. Ancient Africa (Prehistory to 500 ce). New York: The Learning Source Ltd, 2001, pp. 250-251.

Tanzania. In. Encyclopedia of Twentieth-Century African History. New York, London: Routledge, 2002, pp. 542-544.

TANZANIA. In. Worldmark Enciclopedia of the Nations, Twelfth Edition, Africa, Vol. 2. States of America, 2006, pp.679-694.

THE COLONIAL SCRAMBLE FOR AFRICA. In. New Encyclopedia of Africa. Vol. I. States of America, 2008, pp. 262.

TWADDLE, Michael. A África Oriental. In. MAZRUI, A.A. História Geral da África vol. VIII - África desde 1935. São Paulo: Ática/UNESCO, 1991, pp. 274-277.

Dados demográficos e etnológicos da Tanzânia. Disponível em < http://joshuaproject.net/international/pt/countries.php> acesso em: 17/07/2013. 
Revista Vernáculo, $n^{\circ} 30,2^{\circ}$ sem/2012

Dados sobre as expedições ao Lago Vitória. Disponível em < http://www.bbc.co.uk/history/historic_figures/speke_john_hanning.sht ml> acesso em 28/09/2013.

Dados sobre as premiações que o documentário recebeu. Disponível em <http://agal-gz.org/blogues/index.php/aesmorga/2007/01/26/ciclo_de_ cinema_ambientalista_lo_pesadel> acesso em: 25/07/2013. 